\title{
Consistency, now what?
}

\author{
Mary Beth Terry ${ }^{1,2}$
}

This is an editorial article commenting on the attempt that Body size in early life and risk of breast cancer has made to find a consistent pattern between body size and breast cancer risk, by looking at how the female body changes from childhood and adolescence into adulthood

Keywords: Breast cancer, Body size, Adolescence

In epidemiology, inconsistencies are quite common, consistency less so. In this issue of Breast Cancer Research, Shawon and colleagues provide more evidence of consistency for the inverse associations between childhood and adolescent body size and breast cancer risk [1]. Consistent with previous literature based on both case-control and cohort studies (e.g., [2-4]), they observe an inverse association between larger body size at age 7 and 18 years and breast cancer risk in over 35,000 women including over 6700 women with breast cancer. Their study, by pooling data from two individual studies, is larger than most allowing greater precision in estimating separate effects by subgroups. The similarity of their findings between both estrogen receptor (ER)-positive and ER-negative breast cancers and in pre- and postmenopausal women suggests that the inverse association with childhood body size and breast cancer risk is applicable across the spectrum of underlying breast cancer risk and not specific to tumor subtypes more commonly seen in young women. The consistency observed in the study subgroups builds on a literature that was already consistent across study designs and with breast cancer risk and two of its strongest risk factors, benign breast disease [5] and mammographic density [6].

Shawon and colleagues [1] use pictograms, previously validated [7] by others with fair to good correlation. In addition, the main comparison in epidemiology, as with Shawon and colleagues, is often between the highest and lowest categories where the error is substantially less than adjacent categories. Pictograms can also be compared with questions about relative comparisons, and Robinson and colleagues reported differences by race in

\footnotetext{
Correspondence: mt146@cumc.columbia.edu

${ }^{1}$ Department of Epidemiology, Columbia University Mailman School of Public Health, 722 West 168th Street, Room 1611, New York, NY 10032, USA

${ }^{2}$ Herbert Irving Comprehensive Cancer Center, Columbia University Medical Center, New York, NY, USA
}

the responses to recalled body size when using absolute categories from pictograms but saw similar inverse associations with adolescent body size when making references to peer group [8]. Inverse associations with breast cancer risk have also been seen for relative comparison (e.g., were you heavier/shorter, taller/lighter than your peers at a particular age) without accompanying pictogeams [2]. Importantly, Ahlgren et al. [9] reported inassociations with breast cancer risk when using ool records. Thus, the observed inverse association is measurements.

Epidemiologic inference, particularly with observational studies, can be enhanced by repeated measures. Shawon and colleagues observed a $10 \%$ reduction in breast cancer risk for those who reduced a major body size category from 7 to 18 years [1], although only $15 \%$ changed a major category of body size. A similar reduction in breast cancer risk from reducing body size categories over adolescence was also seen by Baer et al. [4], but when Baer and colleagues further adjusted for body size category at the time of the first measurement there was no longer any assocition highlighting the methodologic challenge of making ference about change from recalled data where stability body size may be partially explained by consistent reponses in category. Prospective studies that measure ldhood and adolescent body size changes are greatly increase or decrease risk over adolescence.

The consistent inverse association between early-life body size and breast cancer risk is matched by a similarly consistent association between larger adult body size and increased breast cancer risk. Given the positive association between large body size in adulthood and breast cancer as well as many other cancers and chronic diseases, and the fact that adult body size is shaped by growth trajectories much earlier in life [10], the 
consistent inverse association with larger body size during childhood and adolescence has largely been ignored from a public health perspective. Unraveling the opposing effects of body size on breast cancer risk requires more evidence from in vitro and animal studies as well as prospective studies in humans that can measure changes in breast tissue characteristics. There exists a growing and compelling set of laboratory data supporting the mechanisms between weight gain and metabolically rich environments in increasing breast cancer risk including inflammation and metabolic processes related to cancer risk and changes to epigenetically regulated genes like BRCA1 [11]. Recently the ability to measure normal changes to breast tissue across adolescence in a non-invasive way has become possible [12]. Interestingly, while increased glucose and nutrients may alter the ability of $B R C A 1$ to function as a tumor suppressor [11], pre-pubertal estrogen exposure may increase the ability of key breast cancer susceptibility genes to decrease breast cancer risk through cellular differentiation [13]. Thus overweight girls, even though they experience an earlier puberty, may have increased breast cell differentiation from pre-pubertal estrogen exposure converted from androgens in their adipose tissue. Epidemiologic studies have helped to rule out menstrual cycle abnormalities as another hypothesis of why overweight adolescent girls may have a decreased risk of breast cancer [14]. Much still needs to be known about the role of the pre-pubertal environment in shaping breast cancer risk and prospective studies that collect pre-pubertal biospecimens and can follow girls throughout adolescence are needed to examine how hormonal, metabolic, and growth factors relate to changes at the breast tissue level. A key link to explaining the inverse association may be through the growth of dense tissue and changes to the architecture surrounding the dense tissue which develops and rapidly grows throughout adolescence [15].

In addition to measuring childhood and adolescent growth prospectively and using pre-pubertal biospecimens to measure whether biomarkers of the pre-pubertal environment help to explain differences in breast tissue characteristics based on body size, there remains another piece of the puzzle that needs to be completed. Specifically, it is unclear whether the breast cancer risk in girls that are larger in childhood and adolescence and are large at birth and infancy differs from the risk in girls who start small and grow rapidly. The inverse association between adolescent body size and breast cancer risk may not be apparent for the former [3]. Epidemiology in its search for consistency is always at its best when driven by questions that arise from inconsistencies and an appreciation of the fact that exposures that operate in one way at a time in life may work in different ways across the life-course as the organs that affect disease etiology are evolving and developing and changing in form and function.

\section{Abbreviation \\ ER: Estrogen receptor}

Acknowledgements

Not applicable.

Funding

Not applicable.

Availability of data and materials

Not applicable.

Author's contributions

MBT is the sole contributor to the article.

Authors' information

No further information.

\section{Competing interests}

The author declares that she has no competing interests.

Consent for publication

Not applicable.

Ethics approval and consent to participate

Not applicable.

\section{Publisher's Note}

Springer Nature remains neutral with regard to jurisdictional claims in published maps and institutional affiliations.

Published online: 21 July 2017

\section{References}

1. Shawon SR, Eriksson M, Li J. Body size in early life and risk of breast cancer. Breast Cancer Res. 2017

2. Coates RJ, Uhler RJ, Hall HI, Potischman N, Brinton LA, Ballard-Barbash R, Gammon MD, Brogan DR, Daling JR, Malone KE, Schoenberg JB, Swanson CA. Risk of breast cancer in young women in relation to body size and weight gain in adolescence and early adulthood. Br J Cancer. 1999;81(1):167-74.

3. Baer HJ, Tworoger SS, Hankinson SE, Willett WC. Body fatness at young ages and risk of breast cancer throughout life. Am J Epidemiol. 2010;171:1183-94.

4. Baer HJ, Colditz GA, Rosner B, Michels KB, Rich- Edwards JW, Hunter DJ, Willett WC. Body fatness during childhood and adolescence and incidence of breast cancer in premenopausal women: a prospective cohort study. Breast Cancer Res. 2005:7:R314-25.

5. Berkey CS, Rosner B, Tamimi RM, Willett WC, Hickey M, Toriola A, Frazier AL, Colditz GA. Body size from birth through adolescence in relation to risk of benign breast disease in young women. Breast Cancer Res Treat. 2017; 162(1):139-49.

6. Hopper JL, Nguyen TL, Stone J, Aujard K, Matheson MC, Abramson MJ, Burgess JA, Walters EH, Dite GS, Bui M, Evans C, Makalic E, Schmidt DF, Ward G, Jenkins MA, Giles GG, Dharmage SC, Apicella C. Childhood body mass index and adult mammographic density measures that predict breast cancer risk. Breast Cancer Res Treat. 2016;156(1):163-70.

7. Must A, Willett WC, Dietz WH. Remote recall of childhood height, weight, and body build by elderly subjects. Am J Epidemiol. 1993;138(1):56-64.

8. Robinson WR, Tse CK, Olshan AF, Troester MA. Body size across the life course and risk of premenopausal and postmenopausal breast cancer in black women, the Carolina Breast Cancer Study, 1993-2001. Cancer Causes Control. 2014;25(9):1101-17.

9. Ahlgren M, Melbye M, Wohlfahrt J, Sørensen TIA. Growth patterns and the risk of breast cancer in women. N Engl J Med. 2004;351:1619-26.

10. Ester WA, Houghton LC, Lumey LH, Michels KB, Hoek HW, Wei Y, Susser ES, Cohn BA, Terry MB. BMI maternal and early childhood determinants of women's body size in midlife: overall cohort and sibling analyses. Am J Epidemiol. 2017;15:1-10. 
11. Di LJ, Byun JS, Wong MM, Wakano C, Taylor T, Bilke S, Baek S, Hunter K, Yang H, Lee M, Zvosec C, Khramtsova G, Cheng F, Perou CM, Miller CR, Raab R, Olopade Ol, Gardner K. Genome-wide profiles of CtBP link metabolism with genome stability and epithelial reprogramming in breast cancer. Nat Commun. 2013;4:1449.

12. Lilge L, Terry MB, Walter J, Pinnaduwage D, Glendon G, Hanna D, Tammemagi ML, Bradbury A, Buys S, Daly M, John EM, Knight JA, Andrulis IL. Non-invasive optical spectroscopic monitoring of breast development during puberty. Breast Cancer Res. 2017;19(1):12

13. Cabanes A, Wang M, Olivo S, DeAssis S, Gustafsson JA, Khan G, HilakiviClarke L. Prepubertal estradiol and genistein exposures up-regulate BRCA1 mRNA and reduce mammary tumorigenesis. Carcinogenesis. 2004;25:741-8.

14. Michels KB, Terry KL, Willett WC. Longitudinal study on the role of body size in premenopausal breast cancer. Arch Intern Med. 2006;166:2395-402.

15. Sherratt MJ, McConnell JC, Streuli CH. Raised mammographic density: causative mechanisms and biological consequences. Breast Cancer Res. 2016;18(1):45. 